\title{
Pemoline and magnesium hydroxide: Memory consolidation following acquisition trials
}

N. PLOTNIKOFF

ABBOTT LABORATORIES, NORTH CHICAGO, ILLINOIS

Medication with a single dose of pemoline and magnesium hydroxide aftec training (acquisition) was found to enhance retention of a jump out response in rats for two weeks. It is suggested that giving the drug after training obviates questions of drug effects on sensory thresholds during acquisition. In the present study, the drug apparently has its effect on the consolidation process.

Earlier studies by Plotnikoff (1966a, b, c) indicated that pemoline and magnesium hydroxide (PMH) enhanced acquisition and retention of a jump out response in rats and also antagonized the amnesic effects of electroconvulsive shock. More recent studies by Kimble \& Beach (1967) and by Frey \& Polidora (1967) suggested that sensory threshold changes in animals given PMH may be involved in the enhanced acquisition. However, they used different methods (80 $\mathrm{dB}$ buzzer instead of low intensity $(30 \mathrm{~dB})$ and $80 \mathrm{~V}$ instead of $140 \mathrm{~V}$ for foot-shock). To obviate problems of motivation, perception (sensory threshold changes), attention (enhanced arousal) with the use of test drugs, McGaugh \& Petrinovich (1965) reported that post acquisition medication facllitates retention by potentiating perseveration processes. The present study was therefore conducted to evaluate the effects of PMH on post trial consolidation when the drug was given after the training acquisition trials.

The test chamber used for all conditioning studies was described previously (Plotnikoff, 1966a, b, c). Essentially, the test apparatus consisted of a wooden chamber (11 $\times 12$ in.) with a grid flooring and an escape platform placed outside of the chamber (left side). The scrambler shock source in our apparatus was a Lehigh Valley unit (LVE Model 13 11SS) with 140 V. The grid bars were 0.5 in. apart and consist of $3 \mathrm{~mm}$ diameter stainless steel rods. Rats were placed on the grid floor through a plastic door (10 in. high and 12 in. wide) from the right side. Preselection of "fast learners" was conducted on the first day with three trials, of the following $30 \mathrm{sec}$ sequence; the first $15 \mathrm{sec}$ inside the chamber without shock or buzzer, followed by $10 \mathrm{sec}$ with buzzer and finally 5 sec with buzzer and shock. Six rats per group were employed. The intertrial interval was 8-12 min. "Fast learners" were defined as those rats who escaped from the test chamber within the first $15 \mathrm{sec}$ by the second and third test trials. On the second day, four groups of fast learners were exposed to 10 acquisition trials. Within 2 min following the 10th acquisition trial, three groups were given 5,10 , and $20 \mathrm{mg} / \mathrm{kg} P M H$ orally (prepared as a suspension in $0.3 \%$ tragacanth) and the control group received tragacanth. One and two weeks later, all four groups. received retention trials (a $30 \mathrm{sec}$ sequence in the test chamber without buzzer or shock).

In the training trials performance was uniform for all four test groups (Table 1). All four groups reached equivalent performance levels by the second trial and maintained this fast jump time over the remaining nine trials. Retention trials conducted one week later in the absence of buzzer or shock demonstrated significant retention in the PMH treated groups compared to controls. All three doses were effective. The mean jump-out times for the PMH groups on the first retention trial were $3.1,3.3$, and 5.1 compared to $19.6 \mathrm{sec}$ for the tragacanth control group. A second test was carried out two weeks after the initial learning trials with essentially similar results.

In this study, PMH has been demonstrated to enhance retention when given following a learning experience. An earlier study in "fastlearners" demonstrated a similar superior retention in PMH tested groups (Plotnikoff, 1966a) following electroconvulsive

Table 1 Post-trial consolidation study with PMH

\begin{tabular}{cccrr}
\hline Acquisition Trial & Group 1 & Group 2 & Group 3 & Group 4 \\
\hline 1 & $17.0 \pm 4.2^{*}$ & $9.5 \pm 2.7$ & $14.3 \pm 2.9$ & $17.3 \pm 3.7$ \\
2 & $7.5 \pm 2.1$ & $6.8 \pm 1.9$ & $11.0 \pm 3.1$ & $7.5 \pm 2.0$ \\
3 & $4.6 \pm 1.1$ & $8.6 \pm 3.7$ & $2.8 \pm 0.4$ & $3.8 \pm 1.1$ \\
4 & $3.1 \pm 1.0$ & $4.6 \pm 2.2$ & $4.0 \pm 1.3$ & $2.6 \pm 0.6$ \\
5 & $3.8 \pm 1.0$ & $3.3 \pm 1.0$ & $3.3 \pm 2.1$ & $1.8 \pm 0.5$ \\
6 & $3.5 \pm 0.7$ & $5.0 \pm 2.4$ & $3.1 \pm 0.7$ & $2.1 \pm 0.4$ \\
7 & $4.8 \pm 2.1$ & $2.1 \pm 0.6$ & $3.5 \pm 1.3$ & $2.0 \pm 0.2$ \\
8 & $3.6 \pm 0.6$ & $2.8 \pm 0.7$ & $4.0 \pm 1.3$ & $2.0 \pm 0.2$ \\
9 & $3.5 \pm 0.5$ & $2.8 \pm 0.7$ & $2.1 \pm 0.3$ & $1.6 \pm 0.2$ \\
10 & $3.3 \pm 0.6$ & $2.5 \pm 0.4$ & $2.6 \pm 0.6$ & $1.8 \pm 0.4$
\end{tabular}

Post-Trial Injection PMH (orally)

Control (Tragacanth) $\quad 5 \mathrm{mg} / \mathrm{kg} \quad 10 \mathrm{mg} / \mathrm{kg} \quad 20 \mathrm{mg} / \mathrm{kg}$

Retention** (One week after acquisition) Trial

$\begin{array}{lllll}1 & 19.6 \pm 3.3 & 3.1 \pm 0.9 & 3.3 \pm 1.1 & 5.1 \pm 2.0 \\ 2 & 13.6 \pm 3.5 & 3.6 \pm 1.2 & 2.6 \pm 0.5 & 2.5 \pm 0.9 \\ 3 & 20.8 \pm 4.4 & 3.3 \pm 0.8 & 5.1 \pm 1.1 & 1.6 \pm 0.4\end{array}$

Retention (Two weeks after acquisition)

\begin{tabular}{lllll}
1 & $18.0 \pm 4.1$ & $7.5 \pm 4.5$ & $5.0 \pm 0.5$ & $3.5 \pm 0.9$ \\
2 & $19.1 \pm 4.9$ & $8.0 \pm 4.0$ & $5.3 \pm 0.4$ & $2.0 \pm 0.2$ \\
3 & $19.6 \pm 4.6$ & $8.0 \pm 4.4$ & $5.1 \pm 0.8$ & $3.0 \pm 0.7$ \\
\hline
\end{tabular}

*Mean jump-out time of six rats \pm standard error

*"Thirty-sec sequence in test chamber without buzzer or shock 
shock. In a recent review, McGaugh \& Petrinovich (1965) cite posttrial consolidation as a direct means of studying drug effects on memory processes and obviating "influences on attentional, perceptual and motivational processes." More recently, Plotnikoff (1967a) reported that PMH enhanced the acquisition and retention of a conditioned photic evoked response in rabbits. Enhancement of synaptic transmission was suggested as a possible mechanism of PMH in the photic evoked response conditioning studies. The present study of posttrial retention would lend further support to the hypothesis that PMH enhances consolidation or "memory storage" processes.

References

BEACH, G., \& KIMBLE, D. P. Activity and responsivity in rats after magnesium pemoline injections. Science, 1967, 155, 698-701.

FREY, P. W., \& POLIDORA, V. J. Magnesium pemoline: Effect on avoidance conditioning in rats. Science, 1967, 155, 1281-1282.
McGAUGH, J. L., \& PETRINOVICH, L. Effects of dugs on learning and memory. Internat. rev. Neurobiol, 1965, 8, 139-196.

PLOTNIKOFF, N. Magnesium pemoline: Enhancement of learning and memory of a conditioned avoidance response. Science, 1966a, 151, 703-704.

PLOTNIKOFF, N. Magnesium pemoline: Antagonism of retrograde amnesia in rats. Fed. Proc., 1966b, 25, 262.

PLOTNIKOFF, N. Magnesium pemoline: Enhancement of memory after electroconvulsive shock in rats. Life Sci, 1966c, 5, 1495-1498.

PLOTNIKOFF, N. Effects of pemoline and magnesium hydroxide on acquisition and retention. San Juan, Puerto Rico, American College of Neuropsychopharmacology, Dec. 6, 1966d, in press.

PLOTNIKOFF, N. Enhancement of retention of the photic evoked response in the rabbit with pemoline and magnesium hydroxide following ECS. Fed. Proc., 1967a, 26, 614.

PLOTNIKOFF, N. Evoked potential correlates of learning and memory with pemoline and magnesium hydroxide. Detroit, Michigan, Soc. Biol. Psychiat., May 6, 1967b, in press.

PLOTNIKOFF, N. Enhancement of conditioned photic evoked responses in the rabbit by pemoline and magnesium hydroxide. Internat. $J$. Neuropsychiat., 1967c, 3, 263-267. 